\title{
ORIGINAL ARTICLE \\ PAROXYSMAL ATRIAL FIBRILLATION OBSERVED ON 48 HOURS HOLTER MONITORING IN PATIENTS WITH SINUS RHYTHM ON ELECTROCARDIOGRAM
}

\author{
Syed Haseeb Raza ${ }^{1}$, Muhammad Sohail Saleemi ${ }^{1}$, Ammar Akhtar ${ }^{1}$, Kashif Ali Hashmi', \\ Muhammad Zubair Zaffar ${ }^{1}$ \\ ${ }^{1}$ Chaudhary Pervaiz Elahi Institute of Cardiology, Multan, Pakistan
}

\begin{abstract}
Objectives: To find out the prevalence of undiagnosed atrial fibrillation and the risk factors associated with atrial fibrillation in patients with complaints of palpitations having normal sinus rhythm on electrocardiogram.

Methodology: The descriptive cross-sectional study was carried out from 1st of January 2017 to 31st of December 2020 at Department of Cardiology, Chaudhary Pervaiz Elahi Institute of Cardiology, Multan. All the patients presented with the complaints of palpitations for six months with normal sinus rhythm on standard 12 lead electrocardiogram were included in the study. After written informed consent, a Holter monitor was applied for $48 \mathrm{~h}$. Data regarding gender, age, diabetes mellitus, hypertension, smoking, obesity, stable ischemic heart disease, valvular or nonvalvular structural heart defect and hyperthyroidism was collected on a preformed Performa for each patient. Presence of atrial fibrillation was noted on Holter monitoring.

Results: Total 1891 patients were studied over the period of 4 years. The mean age of the studied population was $55.99 \pm 16.28$ years. There was male dominance with $70.3 \%(\mathrm{n}=1329)$ males and $29.7 \%(n=562)$ females. $12.50 \%(n=236)$ patients had been diagnosed with atrial fibrillation on Holter monitoring. Age group of patients with age more than 75 years has high burden of atrial fibrillation (31.34\%).

Conclusion: A large number of studied population has been diagnosed with atrial fibrillation on Holter monitoring who presented with palpitation and have normal sinus rhythm on electrocardiogram.
\end{abstract}

Keywords: Paroxysmal atrial fibrillation, Holter monitoring, sinus rhythm, electrocardiogram

Citation: Raza SH, Saleemi MS, Akhtar A, Hashmi KA, Zaffar MZ. Paroxysmal Atrial Fibrillation observed on 48 hours Holter Monitoring in Patients with Sinus Rhythm on Electrocardiogram. Pak Heart J. 2021;54(02):148-152. DOI: https://doi.org/10.47144/phj.v54i2.2090

\section{INTRODUCTION}

Cardiovascular diseases (CVD) alone account for nearly $10 \%$ of the worldwide burden of diseases and it is expected to rise up to $15 \%$ by the end of $2020 .{ }^{1}$ CVD comprises not only of ischemic heart disease but it also involves valvular heart diseases, structural defects, peripheral vascular diseases and arrhythmias. Among arrhythmias paroxysmal atrial fibrillation (AF) is the most common cardiac arrhythmia. ${ }^{2}$ Paroxysmal AF is an episode of AF that can terminate spontaneously or with intervention in less than 7 days $^{3}$ atrial fibrillation has debilitating effects not only on the health related quality of life but also on the psychological status of the patient. ${ }^{4}$

Atrial fibrillation is a global health care problem with evidence suggesting an increase in its incidence and prevalence all over the world. ${ }^{5}$ Complication of AF like stroke and other thromboembolic events are important cause of death and disability. ${ }^{6}$ It is estimated that in year 2050 Asia will have 72 million patients with $\mathrm{AF}$ with an estimation of 2.9 million people suffering from $\mathrm{AF}$ associated stroke alone. ${ }^{2}$ In literature hospital- and community-based $\mathrm{AF}$ prevalence ranged from $0.37 \%$ to $3.56 \%$ and $2.8 \%$ to $15.8 \%$, respectively. ${ }^{7}$ Previously, the diagnosis of AF was difficult as it was made primarily by standard 12-lead electrocardiogram at the time of symptoms. ${ }^{6}$ If $\mathrm{AF}$ terminates spontaneously before seeking medical help or visit to health care center, its diagnosis becomes difficult with the help of standard ECG. But now with the advent of new technologies that allows continuous long-term electrocardiographic monitoring and advancements in holter monitoring has revealed a high prevalence of subclinical and paroxysmal AF in selected populations. ${ }^{6}$

Our institute is the largest referral hospital for diagnosis and management of CVD in the South Punjab Region of Pakistan. Seeing the rising trend of $\mathrm{AF}$ and a high prevalence rate of $\mathrm{AF}$ worldwide we decided to conduct a study to see the prevalence of undiagnosed $\mathrm{AF}$ in our local population and the 
risk factors associated with AF. With the help of this study we will be able to find out the burden of undiagnosed AF and help us to deduce that whether the further workup of patients with palpitations and normal sinus rhythm on ECG is of any benefit or not.

\section{METHODOLOGY}

This cross-sectional studied was carried out in outpatient department of Cardiology at Chaudhary Pervaiz Elahi Institute of Cardiology, Multan for 4 years from $1^{\text {st }}$ of January 2017 to $31^{\text {st }}$ of December 2020. After taking ethical approval from the Ethical Review Committee of the hospital and informed consent, subjects were enrolled in the study. All the patients presented in outpatient department of cardiology unit with the complaints of palpitations for six months with normal sinus rhythm on standard 12 lead electrocardiogram were included in the study. Patients with history of diagnosed paroxysmal, persistent or permanent AF in the past, patients with history of use of proarrythmic drugs, antiarrythmic drugs for any sort of previously registered arrhythmia other than AF and history of illicit drugs use were excluded from the study. Data regarding gender, age, diabetes mellitus, hypertension, smoking, obesity, stable ischemic heart disease, valvular or nonvalvular structural heart defect and hyperthyroidism was collected on a preformed performa for each patient. Patients were considered to have hypertension if they had documented arterial pressure of more than 140/90 $\mathrm{mmHg}$ twice at different occasions or were being treated with antihypertensive medications for two or more years. Patients were considered diabetics if they were taking insulin or oral hypoglycemic agents for two or more years. Patients who had no idea of their diabetic status was considered diabetics if they have fasting blood glucose $>126 \mathrm{mg} / \mathrm{dL}$. Patients having body mass index of $30 \mathrm{~kg} / \mathrm{m}^{2}$ or more was considered obese. Smokers were defined as an adult who has smoked 100 cigarettes in his or her lifetime and who currently smokes cigarettes. Hyperthyroidism was labeled if patient had raised serum T3 and T4 level. Stable ischemic heart disease was labeled if patient has history of angina well controlled with medications. Valvular heart defect was labeled if patient had been diagnosed with mitral stenosis on echocardiography performed by a consultant cardiologist with at least 3 -year post fellowship experience or have a history of metallic valve replacement on medical records. Nonvalvular structural heart defect was labeled if patient had diagnosis of any valve involvement other than mitral valve or congenital heart defect like atrial septal defect on echocardiography performed by a consultant cardiologist with at least 3-year post fellowship experience. All patients had a standard 12-lead ECG at admission. In absence of any evidence of $\mathrm{AF}$, the patients were recruited into the study group and after written informed consent, a holter monitor was applied for 48 hours. Electrographic recordings were later on analyzed offline with a focus on detecting atrial fibrillation. Heart rate and RR variability plots were checked for patterns suggestive of atrial fibrillation. Supraventricular premature complexes, supraventricular tachycardia, ventricular premature complexes and ventricular tachycardia as detected by the automated software algorithm were scanned. Electrographic strips representing fastest and slowest heart rates were also inspected and intensive manual review was also undertaken for most of the cases. Presence of atrial fibrillation was defined as at least 1 period of $>30 \mathrm{~s}$ duration. Paroxysmal AF is defined as a self-terminating sequence of $>30$ seconds of irregular RR intervals and the presence of fibrillatory $\mathrm{P}$ waves. Holter ECGs were performed on a SCHILLER MT-200 system (Schiller AG) and independently analyzed by 2 cardiologists.

Computer software 20.0 was used to enter and then analyze the data. Mean and standard deviation was calculated for quantitative variables and frequency and percentages were calculated for qualitative variables. Chi square test was applied to see significance of presence of AF with explanatory variables. A p-value of less than 0.05 was considered significant. Odds ratio along with $95 \%$ confidence interval were also calculated.

\section{RESULTS}

Total 1891 patients were studied over the period of 4 years. The mean age of the studied population was $55.99 \pm 16.28$ years with the minimum age of 7 years and maximum age of 90 years. There was male dominance with $70.3 \%(n=1329)$ males and $29.7 \%$ $(\mathrm{n}=562)$ females. Out of 1891 patients, $44 \%$ $(\mathrm{n}=832)$ were diabetics, 52\% $(\mathrm{n}=983)$ were hypertensive, $39 \% \quad(n=737)$ were obese, $41 \%$ $(n=775)$ were smokers, $30 \% \quad(n=567)$ had stable ischemic heart disease, $22 \% \quad(n=416)$ had hyperthyroidism, $8.86 \%(\mathrm{n}=164)$ had valvular heart defect and $5.07 \%(n=96)$ had nonvalvular structural heart defect in our studied population. Figure 1 shows the percentage of AF in our studied population. Figure 2 shows the percentage of AF among males and females. Table 1 shows the frequency of patients in different age group and frequency of patients with AF in each age group. Table 2 shows the number of patients with AF 
among all risk factors along with odds ratio with 95 $\% \mathrm{CI}$ and p-value.

\section{$\square$ No atrial fibrillation $\square$ Atrial fibrillation}

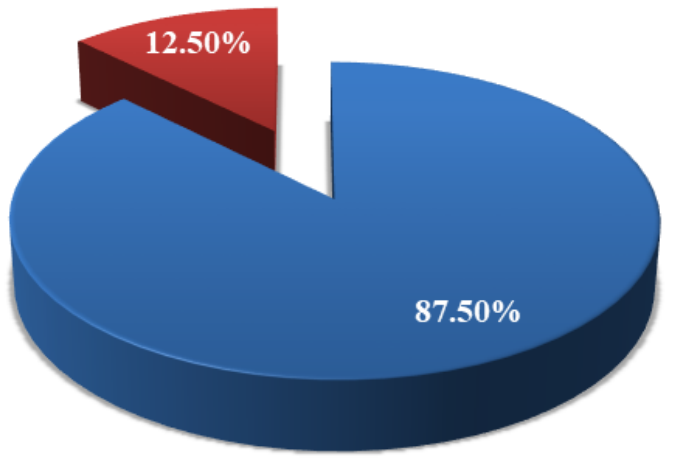

Figure 1: Percentage of AF in our studied population

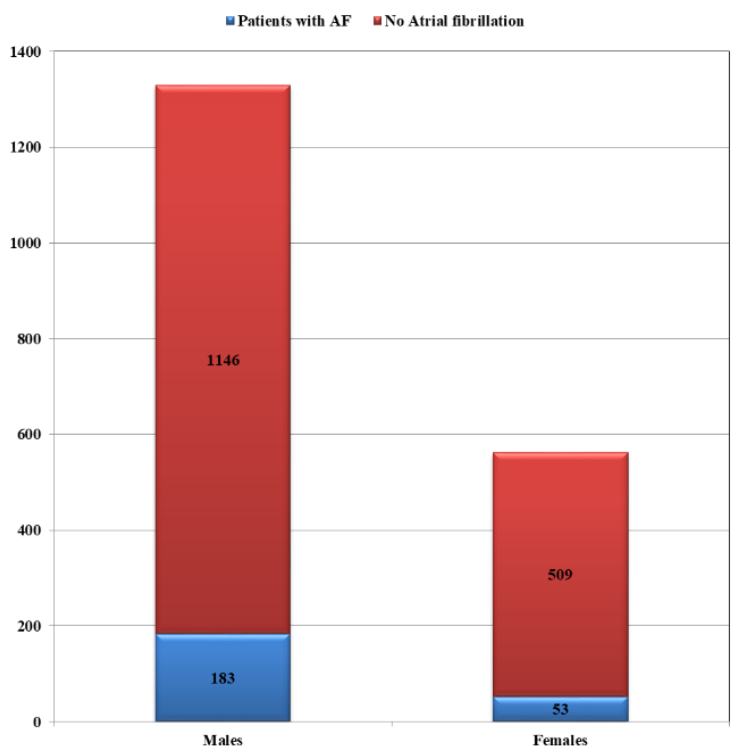

Figure 2: Frequency of males and females with AF (p-value $=0.009)$

Table 1 Frequency of AF in different age groups

\begin{tabular}{|l|l|l|}
\hline Age group & Total patients & Patients with AF \\
\hline Less than 20 years & $58(3.1 \%)$ & $10(17.24 \%)$ \\
\hline 20-40 years & $262(13.9 \%)$ & $11(4.2 \%)$ \\
\hline $40-60$ years & $760(40.2 \%)$ & $58(7.63 \%)$ \\
\hline $60-75$ years & $610(32.3 \%)$ & $94(15.41 \%)$ \\
\hline
\end{tabular}

\begin{tabular}{|l|l|l|}
\hline More than 75 years & $201(10.8 \%)$ & $63(31.34 \%)$ \\
\hline$P$-value $<0.001$ & \\
\hline
\end{tabular}

Table 2 Association of AF with different risk factors

\begin{tabular}{|l|c|c|c|}
\hline Risk Factor & $\begin{array}{c}\text { Patients with } \\
\text { risk factor } \\
\text { having AF }\end{array}$ & $\begin{array}{c}\text { Odds } \\
\text { Ratio } \\
\text { [95\% CI] }\end{array}$ & P-value \\
\hline Diabetes & $\begin{array}{c}132 \\
(15.9 \%)\end{array}$ & $\begin{array}{c}1.73 \\
{[1.31-2.28]}\end{array}$ & $<0.001$ \\
\hline Hypertension & $\begin{array}{c}164 \\
(16.8 \%)\end{array}$ & $\begin{array}{c}2.32 \\
{[1.73-3.12]}\end{array}$ & $<0.001$ \\
\hline Obesity & $\begin{array}{c}126 \\
(17.1 \%)\end{array}$ & $\begin{array}{c}1.99 \\
{[1.52-2.63]}\end{array}$ & $<0.001$ \\
\hline Smoking & $\begin{array}{c}105 \\
(13.6 \%)\end{array}$ & $\begin{array}{c}1.17 \\
{[0.89-1.55]}\end{array}$ & 0.21 \\
\hline Stable IHD & $\begin{array}{c}157 \\
(27.7 \%)\end{array}$ & $\begin{array}{c}6.03 \\
{[4.50-8.08]}\end{array}$ & $<0.001$ \\
\hline Hyperthyroidism & $\begin{array}{c}112 \\
(26.9 \%)\end{array}$ & $\begin{array}{c}4.01 \\
{[3.02-5.33]}\end{array}$ & $<0.001$ \\
\hline $\begin{array}{l}\text { Valvular heart } \\
\text { defect }\end{array}$ & $\begin{array}{c}65 \\
(39.6 \%)\end{array}$ & $\begin{array}{c}5.07 \\
{[4.20-8.47]}\end{array}$ & $<0.001$ \\
\hline $\begin{array}{l}\text { Nonvalvular } \\
\text { structural heart } \\
\text { defect }\end{array}$ & $\begin{array}{c}30 \\
(31.3 \%)\end{array}$ & $\begin{array}{c}3.5 \\
{[2.22-5.53]}\end{array}$ & 0.001 \\
\hline
\end{tabular}

\section{DISCUSSION}

Atrial fibrillation causes thrombus formation within the atria, particularly the left atrial appendage, which can cause thromboembolic events increasing the risk for ischemic stroke and other arterial thromboembolism affecting millions of people worldwide. ${ }^{8}$ The literature has shown that patients having paroxysmal AF may be at higher thromboembolic risk due to intermittent organized contraction of the atria following periods of AF. ${ }^{9}$ The current guidelines recommend anticoagulation for prevention of thromboembolic events based on clinical risk stratification for paroxysmal atrial fibrillation. ${ }^{3}$ So for this reason diagnosis of paroxysmal AF is very important. This study guides us regarding the prevalence of undiagnosed paroxysmal AF in South Punjab which not only helps us in decision regarding anticoagulation but also helps in decision regarding management strategy.

The incidence and prevalence of AF have increased in recent years, although great variability still exists in literature from Asian countries. ${ }^{7}$ A metaanalysis of 58 articles from 8 Asian countries shows prevalence of community based AF from $2.8 \%$ to $15.8 \%{ }^{7}$ We have found $\mathrm{AF}$ in $12.50 \%$ of our studied population which lies within the range reported by Bai $\mathrm{Y}$ et al. $^{7}$ in their metaanalysis.

Literature has reported that men are more prone to develop AF as compared to females. ${ }^{10}$ On average, women develop AF 10 years later than men. ${ }^{11}$ It is reported that prevalence is lower in women (373 per $100,000)$ than in men $\left(596\right.$ per 100,000). ${ }^{5}$ We have also found the similar results in our study that $13.77 \%$ (183) men have AF as compared to women $(9.43 \%)$. 
The age dependency of $\mathrm{AF}$ is also well known. ${ }^{12}$ Feinberg et al reported that the prevalence of AF is 2.3\% in people older than 40 years and $5.9 \%$ in those older than 65 years. ${ }^{13}$ Approximately $70 \%$ of individuals with AF are between 65 and 85 years of age. ${ }^{13}$ For patients older than 80 years, the corresponding rate is approximately $10 \% .{ }^{14}$ We have also found $15.41 \%$ patients with $\mathrm{AF}$ among age group 60 to 75 years and $31.34 \%$ patients with $\mathrm{AF}$ among age group of more than 75 years. This shows that older age group is at higher risk of developing paroxysmal $\mathrm{AF}$ as compare to younger age group.

Hypertension and AF often coexist. Because of its higher prevalence in the population, hypertension accounts for more cases of $\mathrm{AF}$ than other risk factors. ${ }^{15}$ Among patients with established $\mathrm{AF}$, hypertension is present in $\approx 60 \%$ to $80 \%$ of individuals. ${ }^{16}$ We have found $16.84 \%$ percent patients of hypertension suffering from $\mathrm{AF}$ with odds ratio of 2.32 (95\% CI 1.73-3.12).

Framingham Heart Study was one of the first to demonstrate an increased risk of $\mathrm{AF}$ in men and women with diabetes. ${ }^{17}$ In a meta-analysis of several cohort and case-control studies, patients with diabetes had a $34 \%$ greater risk of developing $\mathrm{AF} \cdot{ }^{18}$ In a population-based case-control study of 311 patients with treated diabetes, the risk of developing AF increased by $3 \% .{ }^{15}$ We have found $15.86 \%$ patients with diabetes who have paroxysmal AF with odds ratio of 1.73 (95\% CI 1.312.28).

Obesity is now the second biggest attributable risk factor for $\mathrm{AF}$ after hypertension. ${ }^{17}$ Together with overweight, it accounted for $17.9 \%$ of all AF cases in the Atherosclerosis Risk in Communities (ARIC) study. ${ }^{18}$ We have found $17.10 \%$ obese patients who have episodes of paroxysmal AF.

Literature has shown that 18-46.5\% patients of AF have been proven to have coronary artery disease. ${ }^{19} \mathrm{We}$ have also found $27.7 \%$ patients of stable ischemic heart disease with AF. Previous studies have also favored our results.

Atrial fibrillation is reported in $10-15 \%$ of patients with hyperthyroidism. ${ }^{20} \mathrm{We}$ have also reported $26.92 \%$ patients of hyperthyroidism with paroxysmal AF. We have reported that $13.55 \%$ smokers with AF having odds ratio of 1.17 (95\% CI 0.89-1.55) Rotterdam Study reported almost identical associations for former and current smokers: Odds ratio of 1.51 (1.07-2.12) and 1.48 $(1.12-1.96)$ for current and former smokers, respectively. ${ }^{21}$

Valvular heart disease is an independent risk factor for AF. Its adjusted relative risk is between 2 and $3{ }^{22}$ The prevalence of valvular disease in the AF population is in the range of $5 \%$ to $9 \%{ }^{23}$ But we found a higher prevalence of $\mathrm{AF}$ in Valvular heart disease patients as compared to reported in literature. We found that $39.63 \%$ patients had AF with odds ratio of 5.07 (95\%CI 4.208.47). We have also found $31.25 \%$ patients with structural heart defect having AF with odds ratio of 3.50 (95\% CI 2.22-5.53). This could be due to late presentation of these patients to the tertiary care hospital and poor compliance to the medication and moreover higher rate of unwillingness to have invasive procedures for management.

This study gives an insight to the burden of undiagnosed paroxysmal AF in patients with history of palpitations having normal rhythm on electrocardiogram. This study shows the importance of proper workup and need of diagnosis in such patients. This study could help in further studies and encourage the treating physicians to make strategies for proper diagnosis and then later plan a treatment strategy if a patient is diagnosed with paroxysmal AF.

This study also have some limitations. First of all this is a single centre, single time, observational study with a small sample size. Secondly this study depicts a burden of undiagnosed paroxysmal AF in society which got diagnosed on 48 hour holter monitoring. It is quite possible that few patients did not get diagnosed even on holter monitoring and may require holter or ambulatory ECG monitoring for longer duration. This study also did not differentiate between different types of valvular and structural heart defects and AF associated with them as this needs a different complete study and it considers being beyond the scope of this study.

\section{CONCLUSION}

There is a high prevalence of undiagnosed paroxysmal $\mathrm{AF}$ in patients presenting with palpitations and having normal sinus rhythm on electrocardiogram.

\section{AUTHORS' CONTRIBUTION}

SHR: Concept and design, data acquisition, interpretation, drafting, final approval, and agree to be accountable for all aspects of the work. MSS, AA, KAH, MZZ: Data acquisition, interpretation, drafting, final approval and agree to be accountable for all aspects of the work.

Conflict of interest: Authors declared no conflict of interest.

\section{REFERENCES}

1. Sarfaraz A, Akhtar P, Rizvi SNH, Karim M. Risk factors of atrial fibrillation in patients with heart failure. Cureus. 2018;10(12):e3774

2. Chiang CE, Wang KL, Lin SJ. Asian strategy for stroke prevention in atrial fibrillation. EP Europace. 2015;17(2):ii31-ii39

3. January CT, Wann LS, Alpert JS, Calkins H, Cigarroa JE, Cleveland JC, et al. 2014 AHA/ACC/HRS guideline for the management of patients with atrial fibrillation: a report of the American College of Cardiology/ American Heart Association Task Force on Practice Guidelines and the Heart Rhythm Society. J Am Coll Cardiol. 2014;64(21):e1-e76

4. Tan HC, Koh KWL, Wu VX, Lim TW, Wang W. Health-related quality of life, psychological distress, and symptom burden in an 
Asian population of outpatients with atrial fibrillation. Heart \& Lung. 2018;47(4):322-8

5. Chugh SS, Havmoeller R, Narayanan K, Singh D, Rienstra M, Benjamin EJ, et al. Worldwide epidemiology of atrial fibrillation: A Global Burden of Disease 2010 Study. Circulation. 2014;129(8):837-47

6. Healey JS, Ailings M, Ha A, Leong-Sit P, Birnie DH, De Graaf JJ, et al. Subclinical atrial fibrillation in older patients. Circulation. 2017;136(14):1276-83

7. Bai Y, Wang YL, Shantsila A, Lip GYH. The Global Burden of Atrial Fibrillation and Stroke: A Systematic Review of the Clinical Epidemiology of Atrial Fibrillation in Asia. Chest. 2017; 152 (4):810-20.

8. Colilla S, Crow A, Petkun W, Singer DE, Simon T, Liu X Estimates of current and future incidence and prevalence of atrial fibrillation in the US adult population. Am J Cardiol. 2013;112(8):1142-7.

9. Go AS, Reynolds K, Yang J, Gupta N, Lenane J, Sung SH, et al. Association of burden of Atrial Fibrillation with risk of Ischemic Stroke in adults With Paroxysmal Atrial Fibrillation: The KPRHYTHM Study. JAMA Cardiol. 2018;3(7):601-8.

10. Pothineni NV, Vallurupalli S. Gender and Atrial Fibrillation: Differences and Disparities. US Cardiology Review. 2018;12(2):103-6.

11. Magnussen C, Niiranen TJ, Ojeda FM, Gianfagna F, Blankenberg S, Njolstad I, et al. Sex differences and similarities in atrial fibrillation epidemiology, risk factors, and mortality in community cohorts: results from the BiomarCaRE Consortium (Biomarker for Cardiovascular Risk Assessment in Europe). Circulation. 2017;136(17):1588-97.

12. Mandalenakis Z, Von Koch L, Eriksson H, Dellborg M, Caidah $\mathrm{K}$, Welin $\mathrm{L}$, et al. The risk of atrial fibrillation in the general male population: a lifetime follow-up of 50-year-old men. Europace. 2015;17:1018-22.

13. Wertheimer G, Bereznicki LR. Exploring the Quality of Anticoagulant Prescribed for Patients With Atrial Fibrillation at the St John of God Hawkesbury District Health Centre, New South Wales, Australia. J Cardiovasc Pharmacol Ther. 2019;24(1):46-53

14. Karamichalakis N, Letsas KP, Vlachos K, Georopoulos S, Bakalakos A, Efrimidis M, et al. Managing atrial fibrillation in the very elderly patient: challenges and solutions. Vasc Health Risk Manag. 2015;11:555-62.

15. Wang A, Green JB, Halperin JL, Piccini JP. Atrial Fibrillation and Diabetes Mellitus. J Am Coll Cardiol. 2019;74 (8): 1107-15.

16. Huxley RR, Filion KB, Konety S, Alonso A. Meta-analysis of cohort and case-control studies of type 2 diabetes mellitus and risk of atrial fibrillation. Am J Cardiol. 2011;108:56-62.

17. Vyas V, Lambiase P. Obesity and Atrial Fibrillation: Epidemiology, Pathophysiology and Novel Therapeutic Opportunities. Arrhythm Electrophysiol Rev. 2019;8(1):28-36.

18. Huxley RR, Lopez FL, Folsom AR, Agarwal SK, Loehr LR, Soliman EZ, et al. Absolute and attributable risks of atrial fibrillation in relation to optimal and borderline risk factors: the Atherosclerosis Risk in Communities (ARIC) study. Circulation. 2011;123(14):1501-8.

19. Kralev S, Schneider K, Lang S, Süselbeck T, Borggrefe M. Incidence and severity of coronary artery disease in patients with atrial fibrillation undergoing first-time coronary angiography. PLoS One. 2011;6(9):e24964.

20. Jayaparasad N, Francis J. Atrial fibrillation and hyperthyroidism. Indian Pacing Electrophysiol J. 2005;5(4):305-11.

21. Chamberlain AM, Agarwal SK, Folsom AR, Duval S, Soliman E $\mathrm{Z}$, Ambrose M, et al. Smoking and incidence of atrial fibrillation: Results from the Atherosclerosis Risk in Communities (ARIC) Study. Heart Rhythm. 2011;8(8): 1161-6.

22. Lakshminarayan K, Anderson DC, Herzog CA, Qureshi AI. Clinical epidemiology of atrial fibrillation and related cerebrovascular events in the United States. Neurologist. 2008;14(3):143-150.

23. US Preventive Services Task Force. Screening for atrial fibrillation with electrocardiography: US preventive services task force recommendation statement. JAMA. 2018;320(5):478-84.

\section{Address for Correspondence:}

Dr. Syed Haseeb Raza, Chaudhary Pervaiz Elahi Institute of Cardiology, Multan, Pakistan.

Email: haseebraza51214@yahoo.com 